\title{
Clarifying the roles of patients in research
}

\author{
Common misunderstandings are a barrier to real progress
}

\author{
Kristin Liabo senior research fellow ${ }^{1}$, Kate Boddy research fellow ${ }^{1}$, Helen Burchmore research clinic \\ coordinator $^{2}$, Emma Cockcroft associate research fellow ${ }^{1}$, Nicky Britten professor ${ }^{1}$
}

${ }^{1}$ NIHR Collaboration for Leadership in Applied Health Research and Care South West Peninsula (PenCLAHRC), University of Exeter Medical School, Exeter, UK; ${ }^{2}$ AccEPT Clinic, Mood Disorders Centre, University of Exeter, Exeter, UK

The term "patient" no longer denotes a passive recipient of healthcare. Patients have demanded, and are increasingly given, the opportunity to influence health services and policies. ${ }^{1}$ Similarly, in health research patients are sought as partners in study design and governance. ${ }^{2}$ This is reflected in The BMJ's patient partnership initiative (www.bmj.com/campaign/patientpartnership), ${ }^{3}$ the Patient-Centred Outcomes Research Institute (PCORI) in the US, ${ }^{4}$ and the National Institute for Health Research (NIHR) in the UK. ${ }^{5}$

Because of the history of (un)ethical conduct in research, including patients as partners in research studies requires clarity about what the role includes. Patients' roles must be defined so that we achieve meaningful patient partnership and well conducted, ethical research.

"The patient" is a construct that assumes an inherent imbalance of power and includes expectations of compliance by those inhabiting it. ${ }^{6}$ That it has taken so long to acknowledge the value patients bring to healthcare and research emphasises just how difficult it can be to broaden their role beyond passively receiving treatment.

Many researchers and health professionals remain confused by patient involvement in research, partly thanks to an unhelpful diversity of terms: in North America it is called engagement, in the Netherlands it's participation. ${ }^{8}$ In the UK the NIHR distinguishes between engagement, involvement, and participation. ${ }^{9}$ Engagement raises research awareness-for example, by providing patients with information about what it means to take part in a clinical trial. Involvement refers to, "where people are actively involved in research projects and research organisations." And participation is when patients contribute data to a study.

\section{Partners or participants?}

Patients have always had a crucial role in health research as providers of data, a role often taken for granted. Patients would donate tissues or their bodies but were excluded from decisions about which tissues or whose bodies should be included and what they would be used for. Henrietta Lacks, for example, never consented to her tissues being used, yet the HeLa cell line contributed to ground breaking discoveries in cancer research. ${ }^{10}$

More recently, health researchers have recognised the importance of incorporating qualitative research on patients' experiences into quantitative studies of those same patients' outcomes. A common misconception is that these qualitative studies equate to patient involvement in research. A qualitative study investigates people's experiences, which are analysed as data and so require ethical approval. The open ended nature of much qualitative research helps to identify patients' priorities, but it is not collaborative in itself. Patients who take on the role of research partners also express views and identify priorities, but these contributions are not analysed as data. To do so would circumvent ethical approval and result in poorly conducted, unethical research.

Other research designs often conflated with "patient involvement" include questionnaires, cognitive interviewing, pilot studies, and reviews of qualitative research. All of these seek the views and experiences of patients as data. Patients involved as partners in research are asked to bring their views and experiences to the table not as data but to contribute to decisions about design, conduct, and reporting of research. They are active collaborators, just like clinicians and managers who are asked for their views and experiences when contributing to research.

To resolve the ongoing confusion, we must make a clear distinction between patients as data providers and patients as active partners. Patient partners are included at all stages of the research process, including in setting the research agenda and analysing data.

It is also possible for patients to be both data providers (participants) and active research partners ${ }^{11}$ - for example, when participants in pilot studies help analyse the data from that pilot and contribute to the next stage of the research. There are ethical challenges to these practices, however, such as how to maintain anonymity of participants in the research report once they become active partners. Again, clearly defining the two roles 
is essential to ensure that someone wearing both hats is aware of the ethical implications.

To avoid conflation of roles, all stakeholders should agree role descriptions at the beginning of a research study. This can help clarify expectation in large multidisciplinary teams for all research partners. Key questions might include, "Is this role one of active research partner or conventional research participant?" or "What will be done with the information provided by patients?" Inviting patients to the same meetings as other research collaborators and treating them as equals in those meetings also clarifies and enhances their status as active partners.

Failure to clarify roles early on risks stigmatising and alienating the people who make all medical research possible. Providers of data and active partners are both crucial to health research, and conflating the two is counterproductive to ethical, valid, and patient focused research.

Competing interests: We have read and understood BMJ policy on declaration of interests and have no relevant interests to declare. The views expressed are those of the authors and not necessarily those of the NHS, the NIHR, or the Department of Health and Social Care.
Provenance and peer review: Not commissioned; externally peer reviewed

1 Richards T, Snow R, Schroter S. Co-creating health: more than a dream. $B M J$ 2016;354:i4550.. 10.1136/bmj.i4550 27633967

2 Stewart R, Liabo K. Involvement in research without compromising research quality. $J$ Health Serv Res Policy 2012;17:248-51. 10.1258/hsrp.2012.011086 22814591

3 Godlee F. Our commitment is to patient partnership. BMJ 2017:356:j939. 10.1136/bmj.j939 28232314

4 PCORI. What we mean by engagement. 2015. https://www.pcori.org/engagement/whatwe-mean-engagement\#PCORIEngagementRubric.

5 National Institute for Health Research. Patients and the public. 2017. https://www.nihr.ac. uk/patients-and-public/.

6 Parsons T. The social system. Free Press, 1951.

7 Shippee ND, Domecq Garces JP, Prutsky Lopez GJ, etal . Patient and service user engagement in research: a systematic review and synthesized framework. Health Expect engagement in research: a systematic review and

8 Abma TA. Patient participation in health research: research with and for people with spinal cord injuries. Qual Health Res 2005;15:1310-28. 10.1177/1049732305282382 16263914

9 Healthtalk. What is patient and public involvement (PPI) in research? Why does it matter? http://www.healthtalk.org/peoples-experiences/improving-health-care/patient-and-publicinvolvement-research/what-patient-and-public-involvement-and-why-it-important

10 Skloot R. The immortal life of Henrietta Lacks. Crown, 2010.

11 Morgan H, Thomson G, Crossland N, Dykes F, Hoddinott PBIBS study team. Combining PPI with qualitative research to engage "harder-to-reach" populations: service user groups as co-applicants on a platform study for a trial. Res Involv Engagem 2016;2:7. 10.1186/s40900-016-0023-1 29062508

Published by the BMJ Publishing Group Limited. For permission to use (where not already granted under a licence) please go to http://group.bmj.com/group/rights-licensing/ permissions 